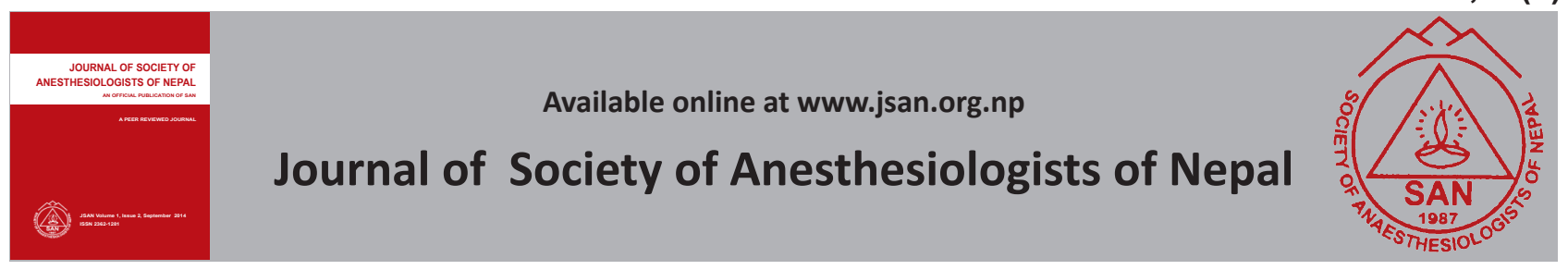

Original Article

\title{
Oral Clonidine in reduction of postoperative nausea and vomiting after laparoscopic cholecystectomy: A double blinded placebo controlled trial
}

Sandip Bhandari*, Madindra Basnet**, Gentle Sunder Shrestha**, Modh Nath Marhatta**

*Department of Anaesthesiology, Shahid Gangalal National Heart Centre, Bansbari, Kathmandu, Nepal.

**Department of Anaesthesiology, Tribhuvan University Teaching Hospital, Maharajgung, Kathmandu, Nepal.

\begin{abstract}
Background: The common adverse effects of laparoscopic cholecystectomy include nausea and vomiting. Surgical pneumoperitoneum can stimulate vagal response and induce the release of various emetogenic substances such as 5-hydroxytryptamine and acetylcholine. We hypothesized that oral Clonidine administered preoperatively reduces the post operative nausea and vomiting following laparoscopic cholecystectomy.
\end{abstract}

ARTICLE I N F O

Article history

Received 16.07.2014

Accepted 05.09.2014

Published 08.09.2014

(C) Authors retain copyright and grant the journal right of first publication with the work simultaneously licensed under a Creative Commons Attribution License that allows others to share the work with an acknowledgment of the work's authorship and initial publication in this journal.

Methodology: In a randomized, double-blinded placebo controlled study, seventy patients undergoing laparoscopic cholecystectomy were assigned to receive either oral Pyridoxine (placebo) or oral Clonidine 200 $\mu$ g 20-30 minutes before conduction of general anaesthesia. We assessed post operative nausea and vomiting and compared its incidence following laparoscopic cholecystectomy with prophylactic use of oral Clonidine or placebo. We also found out the requirements of rescue antiemetic medication (Ondansetron and Promethazine) for post operative nausea and vomiting after prophylactic use of oral Clonidine or Placebo.

Results: Three patients in Clonidine group and 12 patients in Placebo group vomited in first two hours. Likewise, 11 and 22 patients vomited in Clonidine and Placebo group over 24 hours respectively. In group Clonidine, 18 patients had nausea in first two hours and 20 patients had nausea over 24 hours. In group Placebo, 33 patients developed nausea in first two hours and over 24 hours. Ten patients in Clonidine group and 19 patients in Placebo group required Ondansetron as rescue antiemetics over 24 hours.

Conclusion: Oral Clonidine given pre-operative to patients undergoing laparoscopic cholecystectomy decrease the incidence of post operative nausea and vomiting.

Key words: Clonidine, laparoscopic cholecystectomy, nausea, vomiting

How to cite this article: Bhandari S, Basnet M, Shrestha GS, Marhatta MN. Oral Clonidine in reduction of postoperative nausea and vomiting after laparoscopic cholecystectomy: A double blinded placebo controlled trial. JSAN 2014;1:76-79.

\footnotetext{
Correspondence: Sandip Bhandari

Department of Anaesthesiology

Shahid Gangalal, National Heart Centre, Bansbari, Kathmandu, Nepal,

Telephone: + 9779851115629

Email: sandipbhandari@hotmail.com
} 
Introduction

Post operative nausea and vomiting (PONV) is one of the most common complications following general anaesthesia. The incidence of PONV after laparoscopic cholecystectomy ranges from $53 \%$ to $77 \%$.' Higher incidence of nausea vomiting has increased the cost of treatment and hospital stay. The increase in nausea vomiting increases the patient distress, dehydration and wound dehiscence. It also delayed oral input and mobilization. Laparoscopic surgery has decreased morbidity as compared to open cholecystectomy. So it is preferred procedure for the symptomatic cholelithiasis. The laparoscopic procedure has made the patient more comfortable with less complication. However, pneumoperitoneum induced by laparoscopy can stimulate vagal response. It induces the release of various emetogenic substances such as 5-hydroxytryptamine and acetylcholine and hence increases nausea and vomiting. Studies have shown that Clonidine also have the antiemetic properties." This double blinded placebo controlled trial was designed to identify whether the use of oral Clonidine decreases the incidence of post operative nausea and vomiting in patient undergoing laparoscopic cholecystectomy.

Material and method

This is the prospective, randomized, placebo controlled double blinded study. There were 70 Patients with either sex of American Society of Anesthesiology Physical status (ASA PS) I and II. They were divided into two groups of 35 patients each. Patients with ages of 18 to 65 years weighing 40 to $80 \mathrm{~kg}$ presenting for laparoscopic cholecystectomy were included in our study. It was conducted over 4 months period in university hospital. Approval obtained from the Institutional Review Board. Pre-anaesthetic evaluation was done in all patients. They were fasted for six hours preoperatively and explained about the nausea scoring system. Premedication was given at the night before and morning of the day of surgery with oral Diazepam. The patients were randomly assigned into two groups, group $C$ (Clonidine group) and group P (Placebo group), by sealed envelope method. Group C patients received Tablet (Tab)

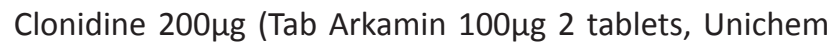
laboratories, India), Placebo Group (Group P) patients received Pyridoxine 20mg (Tab Pyvita 10mg 2 tablets, lotus Pharmaceutical, Nepal). The study medication was given approximately 30 to 60 minutes before surgery. Noninvasive Blood Pressure (BP), Heart Rate (HR) and oxygen saturation $\left(\mathrm{SpO}_{2}\right)$, ECG were monitored. The conduct of general anaesthesia was standard balanced technique and similar in all patients. Oral feeding was started after six hours. In post-operative period analgesia was provided with Ketorolac 30mg and Paracetamol 300mg intravenously eight hourly. Rescue analgesia was provided with Pethidine 50mg intramuscularly.

Nausea score was measured using a numerical four point ordinal scale score, classified as No nausea-0, Nausea without retching-1, Nausea with retching-2 and Nausea with urge to vomit-3. Vomiting was recorded as present or absent. Nausea was assessed at 30 minutes interval for first two hours, then every hour for next four hour and then six hourly till $24^{\text {th }}$ hour of surgery. Rescue antiemetic was given if patient vomited or asked for antiemetic or their nausea score was more than two. The first line antiemetic was intravenous Ondansetron $4 \mathrm{mg}$. Intravenous Promethazine $12.5 \mathrm{mg}$ was used as second rescue drug, if nausea and/or vomiting persisted after 10 minutes of first drug. Sedation, secondary end point of the study, was assessed with Ramsay sedation scale. It was recorded every 30 minutes for first two hours of study. The side effects of test drugs like headache, dry mouth, sedation and hypotension were recorded. Requirement of rescue antiemetic and frequency of their use, total Pethidine consumption in 24 hours were also recorded.

Sample size was calculated on the basis of the probability sample where prevalence of laparoscopic cholecystectomy was compared to the total number of major abdominal surgery in the research area. All data were entered in Microsoft office Excel worksheet 2007. For the analysis of the data, Statistical Package for the Social Sciences (SPSS) 20 was used. A p value less than 0.05 was considered significant. Chi square test, Independent t test, Paired $t$ test were used for data analysis.

\section{Results}

All seventy patients completed the study. The demographic variables were similar between groups (Table 1). There were more of female patients in both the groups. Baseline hemodynamic parameters were comparable. The risk factor for the development of PONV- female population $(p=0.74)$, history of PONV $(p=0.60)$ and history of current smoking $(p=1)$ were comparable in both the groups. None of the patient enrolled in the study had history of Motion sickness.

Table 1: Demographic variables

\begin{tabular}{llll}
\hline & $\begin{array}{l}\text { Group P } \\
\text { (mean } \pm \text { SD) }\end{array}$ & $\begin{array}{l}\text { Group } \\
\text { C(mean } \pm \text { SD) }\end{array}$ & p-value \\
\hline Age (years) & $43.20 \pm 13.75$ & $39.46 \pm 10.75$ & 0.20 \\
$\begin{array}{l}\text { Weight } \\
\text { (kilogram, kg) }\end{array}$ & $56.74 \pm 9.24$ & $60.03 \pm 10.82$ & 0.17 \\
$\begin{array}{l}\text { Height } \\
\text { (metre,m) }\end{array}$ & $1.59 \pm 0.07$ & $1.56 \pm 0.08$ & 0.09 \\
& & & \\
\hline
\end{tabular}

SD- standard deviation 


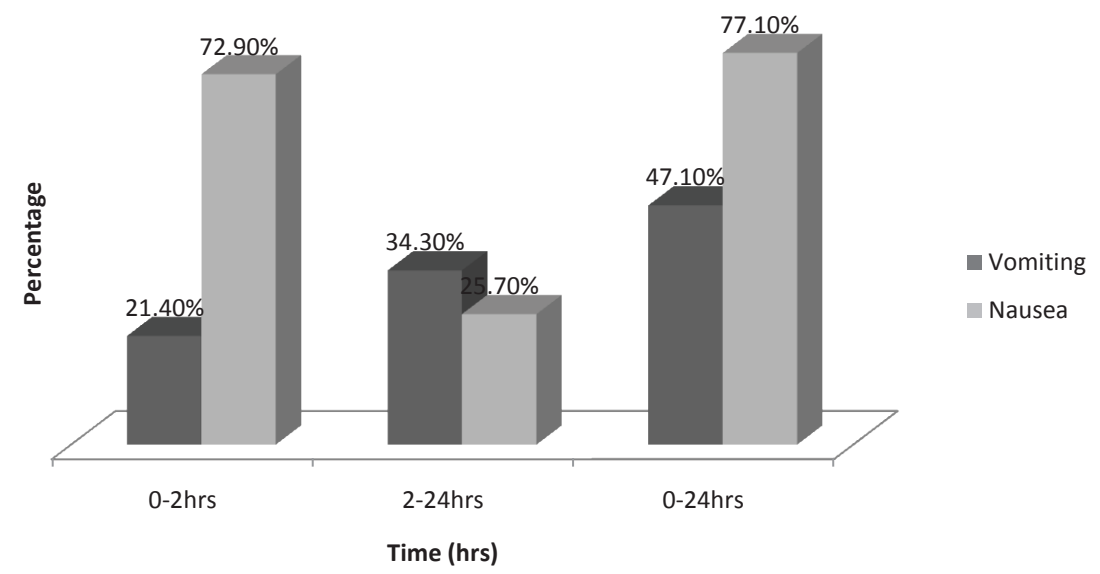

Figure 1: Overall incidence of nausea and vomiting (\%)

Table 2: Comparison of nausea and vomiting between the groups

\begin{tabular}{|c|c|c|c|c|c|c|}
\hline & Vomiting & & & Nausea & & \\
\hline & Clonidine & Placebo & $\mathbf{p}$ & Clonidine & Placebo & $\mathbf{P}$ \\
\hline $0-2 \mathrm{hrs}$ & $4.30 \%(3)$ & $17.10 \%(12)$ & 0.044 & $25.70 \%(18)$ & $47.10 \%(33)$ & 0.001 \\
\hline $2-24 \mathrm{hrs}$ & $11.40 \%(8)$ & $22.90 \%(16)$ & 0.008 & $7.10 \%(5)$ & $18.60 \%(13)$ & 0.029 \\
\hline $0-24 \mathrm{hrs}$ & $15.70 \%(11)$ & $31.40 \%(22)$ & 0.009 & $30.00 \%(21)$ & $47.10 \%(33)$ & 0.001 \\
\hline
\end{tabular}

Nausea and vomiting were significantly less in clonidine group as compared to control group. Less number patients in Clonidine group received rescue anti-emetic. None of the patients in study group received second line antiemetic. Two patients in Placebo group needed second line anti-emetic. Use of rescue analgesic was comparable between the groups. Similarly, sedation scores were also comparable. Side effects like dry mouth, headache, and hypotension were comparable between the groups.

\section{Discussion}

Our study showed that premedication with Clonidine decreases the incidence of nausea $(30.00 \%$ vs $47.10 \%)$ and vomiting $(15.70 \%$ vs $31.40 \%)$ in patients undergoing laparoscopic cholecystectomy. This improvement was achieved without any increase in post-operative sedation or clinically important side effects of Clonidine.

The finding of our study was similar to the study done by Javaherfroosh et al. ${ }^{11}$ In their study in 68 patient undergoing laparoscopic gynaecological surgery, nausea and vomiting was significantly less in Clonidine groups as compared to Placebo group $(p<0.05)$. Our finding was also similar to finding of study done by Taheri et $\mathrm{al}^{12}$. They found 33\% patients in placebo and $67 \%$ patient in Clonidine group did not have PONV $(p<0.01)$ after use of oral Clonidine in ear surgery patient. Likewise our finding was similar to the finding of the study conducted by Oddby-Muhrbeck et $\mathrm{al}^{13}$, where oral Clonidine was associated with higher overall number of PONV free individual compared to placebo in patients undergoing breast cancer surgery. The finding of our study was also similar to finding of the study conducted by Miwaka et al and Handa et al.

Clonidine has been used as anti hypertensive for more than a century. It is used as oral medication and is comparatively cheaper and easily available. Its effect on Imidazole or other receptor in CNS contributes to antiemetic properties. ${ }^{11,}$ Other possible causes of antiemetic properties are significant reduction in the requirement of volatile anesthetic agents, generalized reduction in sympathetic outflow and reduction of the requirement of opioids analgesics in post operative period. ${ }^{11,12,13}$ It blunts the hemodynamic changes produced by the laparoscopic procedure. ${ }^{14}$ Along with this Clonidine also acts on imidazoline receptor as antagonist to inhibit sympathetic activity and lower blood pressure, mediate sedation and anxiolysis. Other side effects of Clonidine include drowsiness, headache, dry mouth, hypersensitivity reaction.

Metoclopramide, frequently prescribed antiemetic, is no better than Placebo. Also it has more adverse effects like extrapyramidal reactions, agitation, hypotension, sinus arrhythmias. Food and Drug Administration has given black box warning due to reports of severe arrhythmias and deaths with the use of Droperidol. Antihistamines are not better than serotonin antagonist with side effects of sedation, drowsiness, urinary retention, dry mouth, blurred vision and extrapyramidal symptoms. Serotonin antagonist (Ondansetron, Granisetron) are more effective and have 
fewer side effects compared to all previous antiemetic drugs. Its most common side effects are headache, dizziness and constipation but it is not free of cardiac side effect in cases of long QT interval causing arrhythmias. Clonidine is devoid of most of these complications and was chosen for the study. However, our study did not compare Clonidine with other anti-emetic drugs.

There was no significant difference in patient distribution in terms of age, weight, height, baseline hemodynamic parameters. The participation of the female patient in both the groups was high because the disease condition is much more common in female population. The difference in ASA PS of the patients was statistically significant between the groups. However, Van den Bosch et al showed that there is no difference in the incidence of PONV in ASA PS I or II patients. So result is not affected by this parameter.

Various risk factors as described by Apfel et al can be confounding for the development of PONV. Female gender, history of PONV, smoking status and opioids used were considered in our study and were comparable. The use of the opioids could be the risk factor hence the fixed dose of Pethidine per kilogram of body weight was used. The effect of duration of anaesthesia for development of PONV varies widely. The duration of anesthesia is directly related to the use of higher doses of opioids, which contributes to the development of PONV. ${ }^{27}$ History of motion sickness is another risk factor. It was included in our study but none of the patient had history of motion sickness. Studies have included the duration of surgery, use of antibiotics, inducing agents, volatile anaesthetic, use of Neostigmine, nasogastric (NG) tube etc as other confounding factors for the development of nausea and vomiting.' All the patients received a single dose of prophylactic antibiotic Ceftraixone before skin incision. Post-operative antibiotics were not prescribed in any of the patients. This antibiotic is a rarer cause of nausea and vomiting. Neostigmine was used in similar dose in both the study and control groups. The NG tube was used whenever there was distended stomach after direct visualization with scope. Moreover, Karger et al $^{29}$ have shown that the routine use of NG tube does not reduce the incidence of PONV.

Patients assigned to Clonidine group have similar opioids consumption compared to the placebo group. These results are also comparable to the study by Mikawa et al. ${ }^{16}$ In Clonidine group, $97.1 \%$ of patients have sedation score of $\leq 3$ and all patients were quiet and responded very well to verbal command at 30 minutes. After that all patient had sedation score less than 4 in both the groups

The limitation of the study was our inability to use Clonidine in per kg body weight basis.

This double blinded randomized controlled study showed that Clonidine premedication 200 $\mathrm{g}$ ghen given an hour before general anaesthesia causes reduction in incidence of post operative nausea and vomiting as compared to Placebo without significant side effects.

\section{References}

1. Eberhart LHJ, Hogel J, Seeling W, Staack AM, Geldner G, Georgieff M. Evaluation of three risk scores to predict postoperative nausea and vomiting. Acta Anaesthesiol Scand 2000;44:480-8.

2. Koivuranta MK, Laraa E, Ryhanen PT. Antiemetic efficacy of prophylactic ondansetron in laparoscopic cholecystectomy. A randomized, doubleblinded, placebo-controlled trial. Anaesthesia 1996;51:52-5.

3. Thune A, Appelgren L, Haglind E. Prevention of postoperative nausea and vomiting after laparoscopic cholecystectomy. Eur J Surg 1995;161:265-8.

4. Hill RP, Lubarsky DA, Phillips-Bute B, Fortney JT, Creed MR, Glass PS et al. Cost-effectiveness of prophylactic antiemetic therapy with ondansetron, droperidol or placebo. Anesthesiology 2000;92:958-7.

5. Begos DG, Modlin IM. Laparoscopic cholecystectomy: from gimmick to gold standard. J Clin Gastroenterol 1994;19:325-30.

6. Yotsui T. Clonidine premedication prevents sympathetic hyperactivity but does not prevent hypothalamo-pituitary-adrenocortical responses in patients undergoing laparoscopic cholecystectomy. J Anesth 2001;15:78-82.

7. Javaherfroosh F, Pipelzadeh MR, Namazi M. Clonidine reduces post operative nausea and vomiting in laparoscopic gyanecology surgery. Pak J Med Sci 2009;25:782-5.

8. Taheri A, Javadimanesh MA, Ashraf $H$. The effect of oral clonidine premedication on nausea and vomiting after ear surgery. Middle East J. Anesthesiol 2010;20:691-4.

9. Oddby-Muhrbeck E, Eksborg S, Bergendhal HT, Muhrbeck O, Lonnqvist PA. The effect of clonidine in postoperative nausea and vomiting in breast cancer surgery. Anesthesiology 2002;96:1109-14.

10. Gan TJ, Meyer TA, Apfel CC, Chung F, Davis PJ, Habib AS et al . Society for Ambulatory Anesthesia Guidelines for the management of Postoperative Nausea and Vomiting. Anesth Analg 2007;105:1615-28.

11. Ramsay MA, Savege TM, Simson BR, Goodwin R. Controlled Sedation with Alphaxalone-Alphadolone. Br Med J 1974;2:656-9.

12. Mikawa K, Nishina K, Maekawa N, Asano M, Obara H. Oral clonidine premedication reduces vomiting in children after strabismus surgery. Can J Anaesth 1995;42:977-81.

13. Handa F, Fujji Y. The efficacy of oral Clonidine premedication in the prevention of postoperative vomiting in children following strabismus surgery. Paediatr. Anesthesia 2001;11:71-4.

14. Anti-Hypertensive drugs. In: Stoelting RK, Hillier SC. Pharmacology \& Physiology in Anesthetic Practice. 4th ed. Philadephia: Lippincot Wiliams; 2007 p 338-51.

15. Wallenborn J, Gelbrich G, Bulst D, Behrends K, Wallenborn, Rohrbach $A$ et al. Prevention of postoperative nausea and vomiting by metoclopramide combined with dexamethasone: Randomised double blind multicentre trial. BMJ 2006;333:324-8.

16. Stinton LM, Shaffer EA. Epidemiology of gallbladder disease: cholelithiasis and cancer. Gut Liver 2012;6:172-87.

17. Bosch JE van den, Moons KGM, Bonsel GJ, Kalkman CJ. Does measurement of preoperative anxiety have added value for predicting postoperative nausea and vomiting? Anaesth Analg 2005;100:152532.

18. Apfel CC, Korttila K, Abdalla M, Kerger H, Turan A, Vedder I et al. A factorial trial of six interventions for the prevention of postoperative nausea and vomiting. N Engl J Med 2004;350:2441-51.

19. Tramer MR, Fuchs-Buder T. Omitting antagonism of neuromuscular block: effect on postoperative nausea and vomiting and risk of residual paralysis. A systematic review. Br J Anaesth 1999;82:379-86.

20. Kerger KH, Mascha E, Steinbrecher B, Frietsch T, Radke OC, Stoecklein K et al. Routine Use of Nasogastric Tubes Does Not Reduce Postoperative Nausea and Vomiting. Anesth Analg 2009;109:768-73. 